\title{
Desdoblamiento de la transformación martensítica en un acero F82H de activación neutrónica reducida
}

\author{
Splitting phenomenon of martensitic \\ transformation in a F82H reduced \\ neutron activation steel
}

\author{
${ }^{1}$ Gerencia Materiales, C.N.E.A., Centro Atómico Constituyentes, Av. Gral. Paz 1499 B1650KNA, San Martín, Buenos \\ Aires, Argentina. \\ e-mail: sebastianferraris@cnea.gov.ar; danon@cnea.gov.ar
}

\section{RESUMEN}

Una de las soluciones más prometedoras al problema del abastecimiento energético global es el acceso a la producción y control de la fusión nuclear. Este proceso, que es llevado a la práctica mediante reactores nucleares de fusión (de los cuales el primer diseño corresponde a los llamados Tokamak's), involucra plasmas de deuterio/tritio a muy alta temperatura, confinados en cámarasde vacío de forma toroidal bajo la influencia de intensos campos magnéticos. Las condiciones hostiles previstas para los componentes estructurales de estos reactores han impulsado el desarrollo de nuevos materiales con propiedades metalúrgicas adaptadas a estas condiciones. En particular, los aceros martensítico-ferríticos de activación reducida (R.A.F.M.'s por sus siglas en inglés) son fuertes candidatos para la construcción de algunos componentes de estos reactores (primera pared de confinamiento y manto reproductor), debido a sus excelentes propiedades físicas. En este trabajo se analizaron 6 muestras de la aleación $F 82 H$, un acero perteneciente al grupo R.A.F.M. Las mismas fueron extraídas de una placa previamente normalizada a una temperatura de $1040^{\circ} \mathrm{C}$ por 38 minutos y revenida a $750{ }^{\circ} \mathrm{C}$ por 60 minutos (condición de recepción). Los especímenes fueron ensayados en un dilatómetro de alta resolución Bähr modelo DIL 805-A. Con este dispositivo se aplicó a las muestras un calentamiento controlado de $5{ }^{\circ} \mathrm{C} / \mathrm{min}$. hasta $1050{ }^{\circ} \mathrm{C}$, seguido de una meseta isotérmica a la misma temperatura durante 15 minutos, para finalmente ser enfriadas en forma continua hasta temperatura ambiente, a distintas velocidades: $1.5 ; 2 ; 3 ; 5 ; 10$ y $50{ }^{\circ} \mathrm{C} / \mathrm{min}$. Las curvas dilatométricas obtenidas luego de los ensayos evidenciaron la presencia del fenómeno de desdoblamiento de la transformación martensítica a bajas velocidades de enfriamiento. Mediante modelos matemáticos simples, basados en datos experimentales, se obtuvieron curvas de fracción de fase transformada (austenitamartensita) y sus respectivas derivadas temporales en función de la temperatura para cada velocidad de enfriamiento. Además,mediante un microscopio electrónico de barrido con cañón de efecto de campo se obtuvieron imágenes de alta resolución de la microestructura de las muestras ensayadas, como complemento al análisis metalográfico de las probetas.

Palabrasclave: Fusión nuclear,aceros (R.A.F.M.), desdoblamiento de la transformación martensítica.

\section{ABSTRACT}

One of the most promising solutions to global energy supply is nuclear fusion. This process, which is implemented in nuclear fusion reactors (from which one of the first designs was the Tokamak), involves deuterium-tritium plasmas at very high temperature, confined in vacuum chambers of toroidal shape under the influence of strong magnetic fields. The hostile conditions underwent by structural components of these reactors drives the development of new materials with metallurgical properties adapted to these conditions. In particular, the so-called reduced activation martensitic-ferritic steels (R.A.F.M.'s) are strong candidates for constructing these reactors components, due its excellent physical properties. In this contribution 6 samples of the alloy F82H, a steel belonging to the R.A.F.M. group, were analyzed. They were extracted from a plate 
normalized at a temperature of $1040^{\circ} \mathrm{C}$ for 38 minutes and tempered at $750^{\circ} \mathrm{C}$ for 60 minutes (as- received condition). The specimens were tested in a high resolution dilatometer Bähr model DIL 805-A. The samples were heated at a controlled rate of $5^{\circ} \mathrm{C} / \mathrm{min}$. up to $1050^{\circ} \mathrm{C}$, followed by an isothermal holding at the same temperature for 15 minutes, to finally be cooled continuously to room temperature at different rates: $1.5,2,3$, 5,10 and $50{ }^{\circ} \mathrm{C} / \mathrm{min}$. The dilatometric curves obtained after the tests showed the presence of a splitting phenomenon of the martensitic transformation at low cooling rates. By simple mathematical models, based on experimental data, curves giving the fraction of transformed phase (austenite-martensita) and their respective temporal derivatives as a function of temperature were obtained for each cooling rate. High resolution images of the tested samples were also obtained using a FEG-SEM, as a complement of metallographic analysis.

Keywords: Nuclear fusion, (R.A.F.M.) steels, splitting phenomenon, martensitic transformation.

\section{INTRODUCCIÓN}

La transformación de fase (austenita-martensita) bajo enfriamiento continuo ha sido extensamente estudiada a lo largo de los años en diversas aleaciones metálicas. La fase martensita comúnmente observada en dichas aleaciones presenta dos morfologías bien definidas, a saber, listón y placa. Los listones de martensita presentan una sub-estructura interna con una gran densidad de dislocaciones, mientras que las placas de martensita están parcial o completamente macladas. La transformación a martensita desde la fase austenita se produce en el intervalo de temperaturas comprendido entre $\mathrm{M}_{\mathrm{s}}$ (comienzo de la transformación) y $\mathrm{M}_{\mathrm{f}}$ (fin de la transformación) por la sub-división de granos de la austenita, de acuerdo con una organización jerárquica en cuatro niveles sobre la base de los dominios cristalinos formados. Inicialmente los granos de austenita se dividen en grupos de listones llamados paquetes. Cada paquete contiene un gran número de bloques, que son grupos de listones con una o dos variantes en la relación de orientación con la austenita primaria, definidas como sub-bloques. Los límites entre los distintos bloques son de alto ángulo, mientras que los sub-bloques están separados por límites de bajo ángulo. El listón individual representa, entonces, el nivel más pequeño de la sub-división [1]. Esta transición estructural-cuya ocurrencia requiere altas velocidades de enfriamiento en los aceros al carbono, y velocidades considerablemente menores en aceros aleados- presenta, bajo ciertas condiciones, una anomalía denominada "desdoblamiento de la transformación martensítica", cuya explicación ha suscitado la formulación de distintas hipótesis en la literatura publicada al respecto. Este comportamiento anómalo ha sido reconocido en varios tipos de aleaciones metálicas y también marginalmente observado en aceros ferríticos 9-12\% Cr tales como T91 y P91 [2] durante el enfriamiento continuo.

En este trabajo se analiza el fenómeno de desdoblamiento de la transformación martensítica durante el enfriamiento continuode un acero $\mathrm{F} 82 \mathrm{H}(7 \mathrm{Cr} 2 \mathrm{WTaN})$ perteneciente al grupo de los llamados aceros de activación neutrónica reducida (R.A.F.M). Dichos aceros han sido postulados como candidatos de referencia para la fabricación de componentes estructurales en los diseños propuestos para los futuros reactores nucleares de fusión [3, 4]. El seguimiento de la transformación se realizó por dilatometría de alta resolución y se caracterizó además la microestructura de las probetas ensayadas por técnicas de microscopía óptica y electrónica de barrido.

\section{MATERIALES Y MÉTODOS}

Se maquinaron 6 probetas de geometría cilíndrica de $10 \mathrm{~mm}$ longitud y $4 \mathrm{~mm}$ de diámetro de la aleación F82H de composición: (C: 0.09, Si: 0.11, Mn: 0.16, P: 0.002, S: 0.002, Cr: 7.71, Ni: 0.02, Mo: 0.003, N: 0.006, Cu: 0.01, Co: 0.005, Ta: 0.02, B: 0.0002, Ti: 0.01, Nb: 0.0001, V: 0.16, Al: 0.003, W: $1.95 \%$ en peso). Las muestras fueron extraídas de una placa normalizada a una temperatura de $1040^{\circ} \mathrm{C}$ por 38 minutos y revenida a $750^{\circ} \mathrm{C}$ por 60 minutos; estos procesos determinaron la condición de entrega del material. Antes de los ensayos, las muestras fueron sometidas a un lavado por ultrasonido para eliminar de la superficie de las mismas cualquier residuo introducido en las etapas previas.

Los especímenes fueron ensayados en un dilatómetro de alta resolución modelo DIL 805-A de la empresa BÄHR. Cada muestra fue alojada individualmente en la cámara de vacío del dispositivo, para posteriormente evacuar la misma mediante una bomba mecánica y una turbo molecular hasta alcanzar una presión final del orden $10^{-6}$ torr. Este procedimiento fue llevado a cabo para evitar la descarburación de las probetas durante el tratamiento a alta temperatura. Cabe destacar que para llevar a cabo el proceso de calentamiento y enfriamiento de las muestras en los ensayos por dilatometría, las mismas fueron alojadas en el centro de un solenoide de 6 espiras de sección cuadrada. Por estas espiras circulaba una corriente eléctrica alterna controlada que generaba un campo electromagnético uniforme en la región central del solenoide. Así, 
las muestras colocadas en esta región fueron sometidas al campo uniforme y de gran intensidad; como resultado de esta exposición los especímenes sufrieron un calentamiento controlado de forma inductiva (efecto Joule).

Bajo estas condiciones, se aplicó a cada espécimen un ciclo térmico que constó de: un calentamiento controlado a una velocidad de $5^{\circ} \mathrm{C} / \mathrm{min}$.-común a todas las muestras- hasta alcanzar la temperatura de $1050^{\circ} \mathrm{C}$, donde las mismas permanecieron en una meseta isotérmica durante 15 minutos, para luego ser enfriadas de forma continua a 6 velocidades distintas, esto es, $1.5,2,3,5,10$ y $50^{\circ} \mathrm{C} / \mathrm{min}$. respectivamente.

La información experimental obtenida luego de los ensayos dinámicos por dilatometría fue condensada en curvas de dilatación en función de la temperatura. Se desarrolló un algoritmo cuantitativo mediante el software libre GNU Octave, aplicando el método de la regla de la palanca [5] a los datos experimentales, para obtener las curvas de fracción transformada (austenita-martensita) respecto de la temperatura para cada velocidad de enfriamiento. Además, mediante modificaciones al algoritmo se obtuvieron curvas de la derivada temporal de la fracción de fase transformada en función de la temperatura para cada velocidad de enfriamiento y valores para las temperaturas de comienzo $\left(\mathrm{M}_{\mathrm{s}}\right)$ y finalización $\left(\mathrm{M}_{\mathrm{f}}\right)$ de la transformación martensítica para cada muestra. Cabe destacar que estos valores de temperaturas $\mathrm{M}_{\mathrm{s}}, \mathrm{M}_{\mathrm{f}}$ fueron obtenidos de manera aproximada a partir de las curvas experimentales dilatación vs. temperatura, proyectando rectas ajustadas -mediante el método de mínimos cuadrados- en las regiones lineales de dichas curvas, esto es, en las regiones anterior y posterior a la transición estructural. Los valores de estas temperaturas fueron definidos, en cada caso, como el valor minimo de la diferencia entre la curva experimental y las rectas obtenidas por regresión lineal. En la Figura 1 se puede observar una representación esquemática de la aplicación del método en las curvas experimentales.

Cabe señalar que la muestra enfriada de manera continua a $50^{\circ} \mathrm{C} / \mathrm{min}$.presentó un comportamiento anómalo durante el desarrollo del ensayo. Esta anomalía se manifestó en la curva temperatura vs. tiempo (rampa térmica programada) mediante una pérdida de la linealidad en la zona de la transformación de fase austenita-martensita y sugiere que el fenómeno de liberación de energía térmica de la muestra producto de la transformación puede ser censado por la termocupla durante el desarrollo de la experiencia en dichas condiciones. Como consecuencia de esto, la medición final de la variable temperatura se vio afectada debido a la doble contribución de energía térmica medida en la muestra, esto es, la energía térmica liberada en forma de radiación producto del calentamiento por efecto Joule, propio del calentamiento inductivo, y la liberación de energía térmica a causa de la transición de fase estructural. Esta irregularidad en la temperatura medida produjo, en la región $\mathrm{M}_{\mathrm{s}}-\mathrm{M}_{\mathrm{f}}$ de la curva de dilatación vs. temperatura, información experimental errónea, esto es, valores diferentes en dilatación para una misma temperatura. Como solución a este problema, se modificó el algoritmo numérico descripto más arriba, para analizar los datos de dilatación vs. tiempo, en los cuales la anomalía térmica no se manifiesta, en lugar de los datos de dilatación vs temperatura. La finalidad de este procedimiento fue garantizar la veracidad del análisis obtenido de los datos experimentales para todas las curvas enfriadas a $50^{\circ} \mathrm{C} / \mathrm{min}$. y presentadas en este trabajo.

Luego de los ensayos por dilatometría, las muestras fueron incluidas en una resina conductora y sometidas a desbaste mecánico utilizando papeles de carburo de silicio de granulometría: 220, 320, 400 y 600 bajo agua, exponiendo el plano medio de cada probeta cilíndrica. Posteriormente, se utilizaron paños cargados de pasta de diamante de 6 y $1 \mu \mathrm{m}$ para darle a las mismas un pulido especular. Las muestras fueron atacadas químicamente con reactivo Vilella para revelar la microestructura subyacente de cada una de ellas.

Mediante un microscopio óptico modelo OLYMPUS BX-60M dotado de una cámara OLYMPUS UC30, se tomaron imágenes de las superficies de las muestras bajo los aumentos de 20X y 50X. Además, se tomaron imágenes de electrones secundarios de alta resolución mediante un microscopio electrónico de barrido con cañón de emisión por campo (FEG-SEM) Zeiss Supra 40 a diversos aumentos, como complemento del análisis metalográfico realizado en cada espécimen.

\section{RESULTADOS}

Las muestras ensayadas en el dilatómetro evidenciaron, durante la transformación de fase austenitamartensita bajo enfriamiento continuo, un desdoblamiento de la misma a bajas velocidades de enfriamiento. Usualmente, esta transición de fase se produce de forma gradual y en una sola etapa en el intervalo de temperaturas $\mathrm{M}_{\mathrm{s}}-\mathrm{M}_{\mathrm{f}}$. En el caso particular de esta aleación y para las velocidades de enfriamiento analizadas, se observó que la transformación fue completada en dos etapas sucesivas. En la etapa inicial de la formación de martensita, una fracción mayoritaria de austenita fue rápidamente transformada. La fracción remanente de austenita fue transformada a martensita en la segunda etapa de la transición, con una velocidad aparente mucho menor respecto de la transformación en la etapa inicial. 


\subsection{Dilatometría}

El desdoblamiento de la transformación martensítica para la aleación F82H se manifestó en las curvas dilatométricas en la presencia de dos máximos locales sucesivos en el intervalo de temperaturas $\mathrm{M}_{\mathrm{s}}-\mathrm{M}_{\mathrm{f}}$. En la Figura 1 puede observarse una representación esquemática del fenómeno de desdoblamiento de la transformación en una curva de dilatación en función de la temperatura.

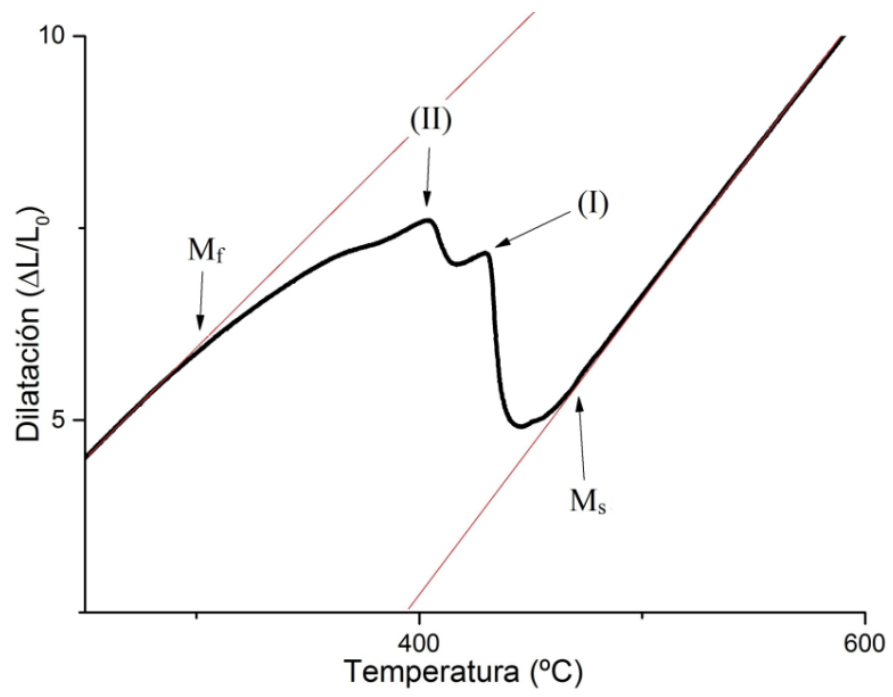

Figura 1: Curva esquemática de dilatación en función de la temperatura; pueden observarse los máximos locales en (I) y (II) confirmando la presencia del fenómeno de desdoblamiento de la transformación martensitica bajo enfriamiento continuo. Los valores aproximados de las temperaturas $M_{s}$ y $M_{f}$ fueron obtenidos mediante el procedimento descripto en el texto.

De los 6 especímenes analizados en este trabajo, 5 mostraron el fenómenode desdoblamiento de la transformación martensítica para las velocidades de enfriamiento de $1.5,2,3,5$ y $10^{\circ} \mathrm{C} / \mathrm{min}$. La muestra enfriada en forma continua a $50^{\circ} \mathrm{C} / \mathrm{min}$. no presentó el fenómeno de transición estructural anómala. En la Figura 2 se exhiben las curvas de dilatación en función de la temperatura para los 6 ensayos realizados.

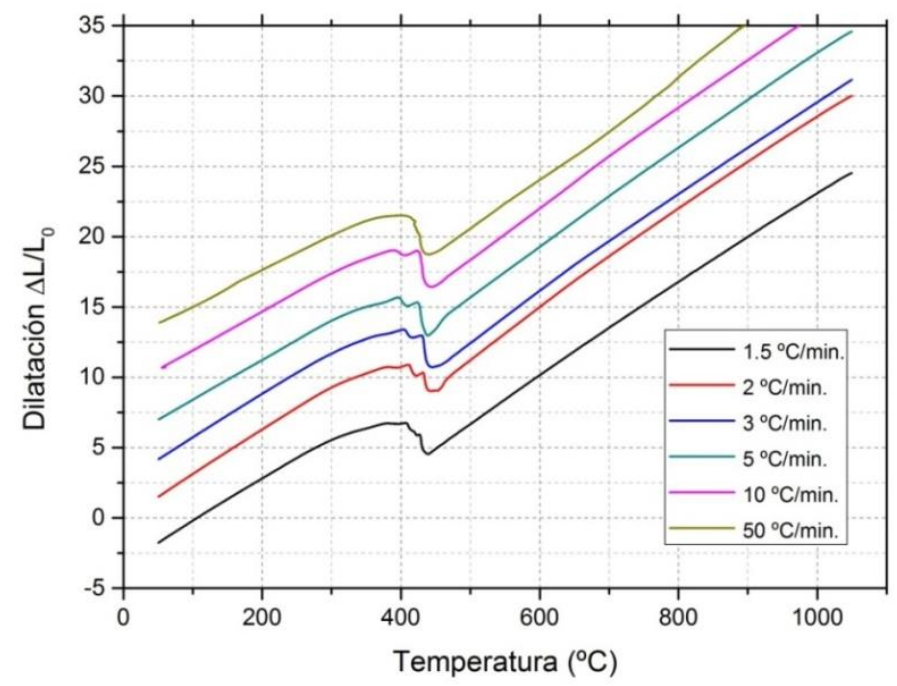

Figura 2: Curvas dilatométricas correspondientes a las 6 muestras ensayadas. Puede observarse que el fenómeno de desdoblamiento de la transformación martensítica se pone de manifiesto en las curvas cuyas velocidades de enfriamiento son: $1.5,2,3,5$ y $10^{\circ} \mathrm{C} / \mathrm{min}$.

La Figura 3 muestra el conjunto de curvas de fracción de fase transformada en función de la 
temperatura para todas las muestras ensayadas.

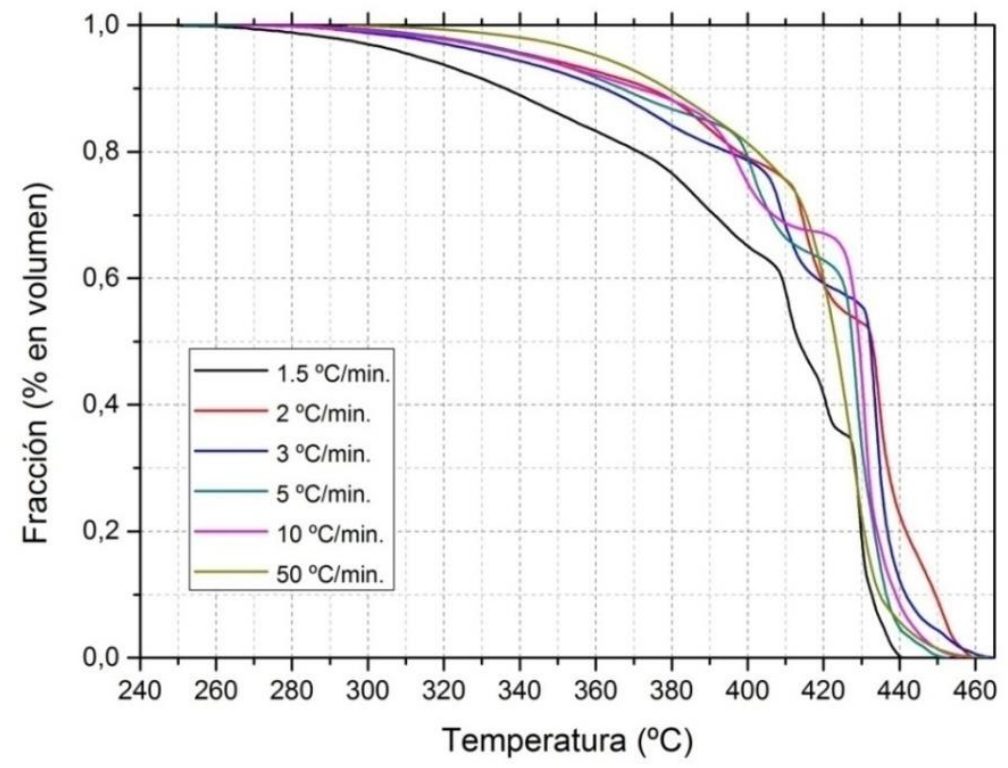

Figura 3: Curvas de fracción de fase transformada austenita-martensita en función de la temperatura para las 6 muestras ensayadas.

Las curvas de fracción de fase transformada austenita-martensita y sus respectivas derivadas temporales en función de la temperatura fueron contrastadas con la finalidad de analizar el fenómeno de desdoblamiento de la transformación martensítica para esta aleación. Las curvas de las derivadas temporales de la fracción transformada en función de la temperatura (o, en otras palabras, de la velocidad de transformación en función de la temperatura) evidenciaron máximos de diversas intensidades correspondientes a la cinética anómala de la transición austenita-martensita. La morfología de las curvas enfriadas a: $1.5,2,3,5 \mathrm{y} 10^{\circ} \mathrm{C} / \mathrm{min}$. mostró similitudes, esto es, cada una de ellas presentaba un máximo principal de gran amplitud seguido de un máximo secundario de amplitud mucho menor en el intervalo de temperaturas correspondiente a $\mathrm{M}_{\mathrm{s}}-\mathrm{M}_{\mathrm{f}}$; en algunos casos, los picos presentaron solapamientos. El número de máximos primarios (absolutos) y secundarios (locales) presentes en cada curva analizada disminuyó en función del aumento de la velocidad de enfriamiento. Para la muestra enfriada a $50^{\circ} \mathrm{C} / \mathrm{min}$. se observó la presencia de un solo máximo principal, es decir, la transformación a martensita se produjo en una sola etapa, definiendo a este valor de velocidad de enfriamiento como un límite natural para la observación del fenómeno de desdoblamiento de la transformación martensitica para el acero F82H. En las Figuras 4, 5 y 6 pueden observarse las diversas curvas de fracción de fase transformada junto a sus respectivas derivadas temporales en función de la temperatura para cada velocidad de enfriamiento.
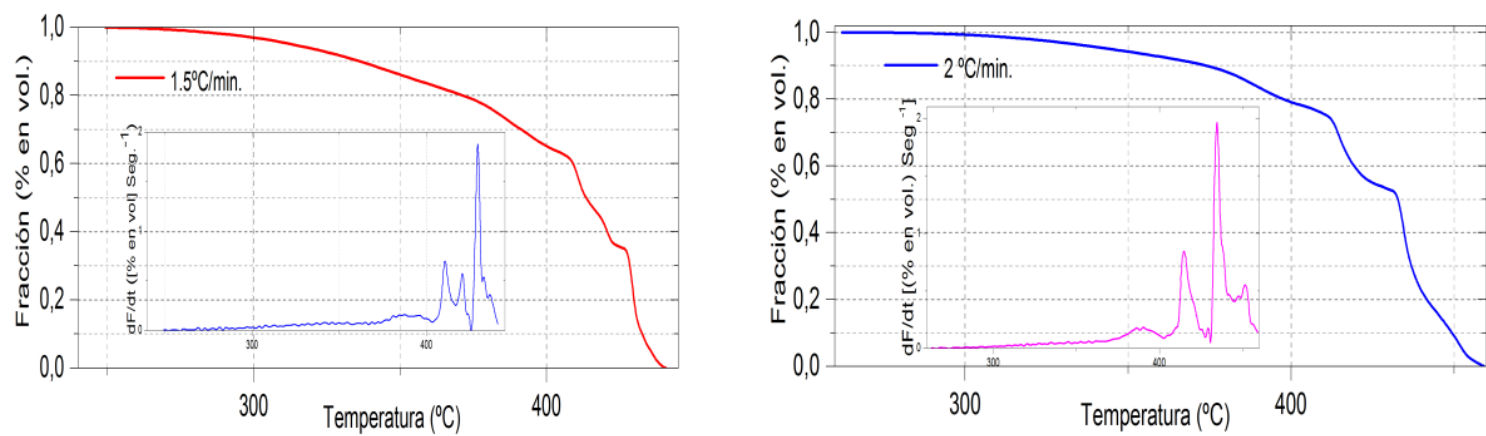

Figura 4: Curvas de fracción de fase transformada austenita-martensita y derivada temporal de las mismas para las velocidades de enfriamiento de 1.5 y $2{ }^{\circ} \mathrm{C} / \mathrm{min}$. Pueden observarse los máximos primarios y secundarios en cada curva. 

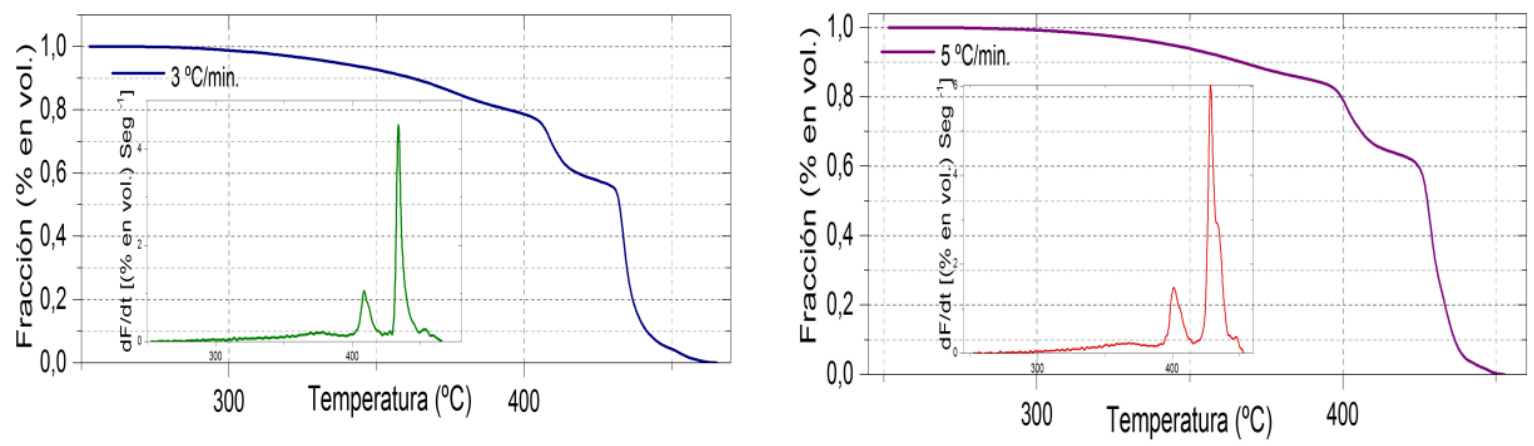

Figura 5: Curvas de fracción de fase transformada austenita-martensita y derivada temporal de las mismas para las velocidades de enfriamiento de 3 y $5^{\circ} \mathrm{C} / \mathrm{min}$. Pueden observarse los máximos primarios y secundarios en cada curva.
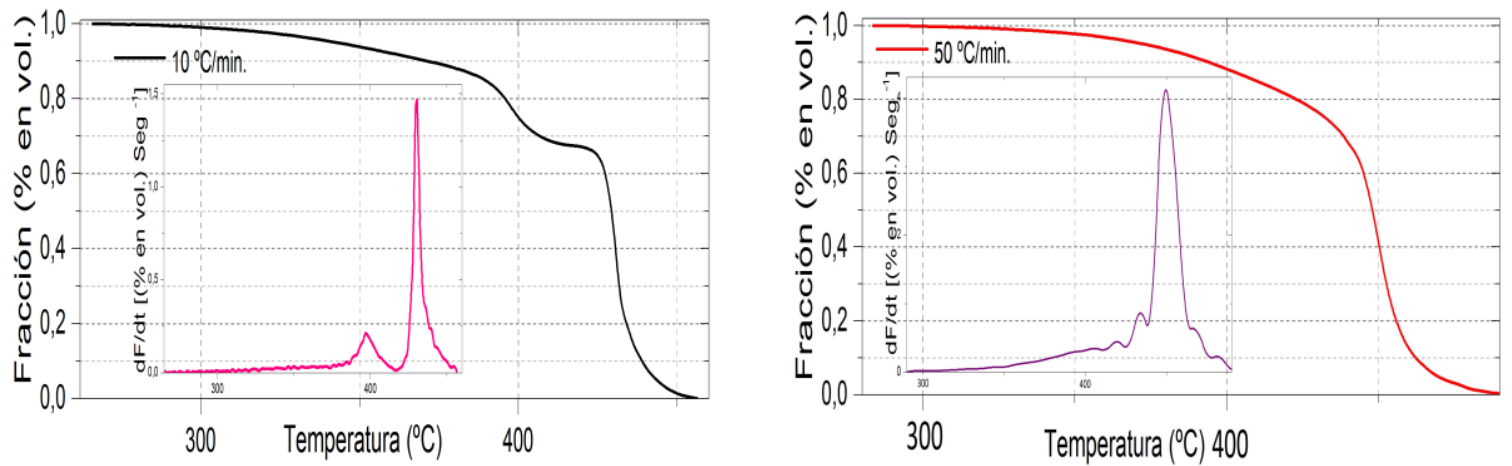

Figura 6: Curvas de fracción de fase transformada austenita-martensita y derivada temporal de las mismas para las velocidades de enfriamiento de 10 y $50^{\circ} \mathrm{C} / \mathrm{min}$. Pueden observarse los máximos primarios y secundarios presentes en la curva de $10^{\circ} \mathrm{C} / \mathrm{min}$. La curva de fracción transformada a $50^{\circ} \mathrm{C} / \mathrm{min}$. no presenta el fenómeno de desdoblamiento de la trasformación martensítica.

\subsection{Microscopia óptica y FEG-SEM}

Las imágenes obtenidas por microscopía óptica luego de las observaciones mostraron una estructura largamente mayoritaria de martensita en listones y la presencia marginal de granos de ferrita nucleados en puntos triples y en ex-bordes de granos austeníticos en cada espécimen. Esta fase, con bordes de grano bien definidos y de morfología poligonal podría haber nucleado durante el enfriamiento o bien durante la permanencia a alta temperatura $\left(1050^{\circ} \mathrm{C}\right)$; bajo esta última hipótesis, se estaría en presencia de ferrita estable en un rango inusual de temperatura para los aceros martensítico-ferríticos de alto Cr. Sin embargo, algunos indicios de un tal comportamiento han sido ya adelantados en la literatura previa para el acero F82H en particular [6].

Por otra parte, las imágenes obtenidas por FEG-SEM confirmaron la existencia de placas de ferrita nucleadas en los ex-bordes de grano austeníticos y puntos triples y además revelaron la presencia de carburos dentro de los listones de martensita. En las Figuras 7 y 8 pueden observarse imágenes tomadas a diversos aumentos por microscopia óptica y FEG-SEM de algunas de las muestras ensayadas para este trabajo; en ambos casos pueden apreciarse las placas de ferrita mencionadas. Por su parte, la densidad aparente de los carburos es mucho mayor en los listones gruesos con respecto a los listones finos (Figuras 8e y 8f). Las imágenes de electrones secundarios de alto aumento permitieron observar también que los carburos formados se disponen en orientaciones preferenciales (Figura 8b) y muestran además una tendencia a la aglomeración en cúmulos (Figura 8d). La morfología de tipo bastoncillo y la existencia de orientaciones preferenciales sugiere que los mencionados carburos podrían corresponder a cementita formada por un proceso de autorevenido, ya informada para aleaciones de composición similar [7, 8, 9]. 

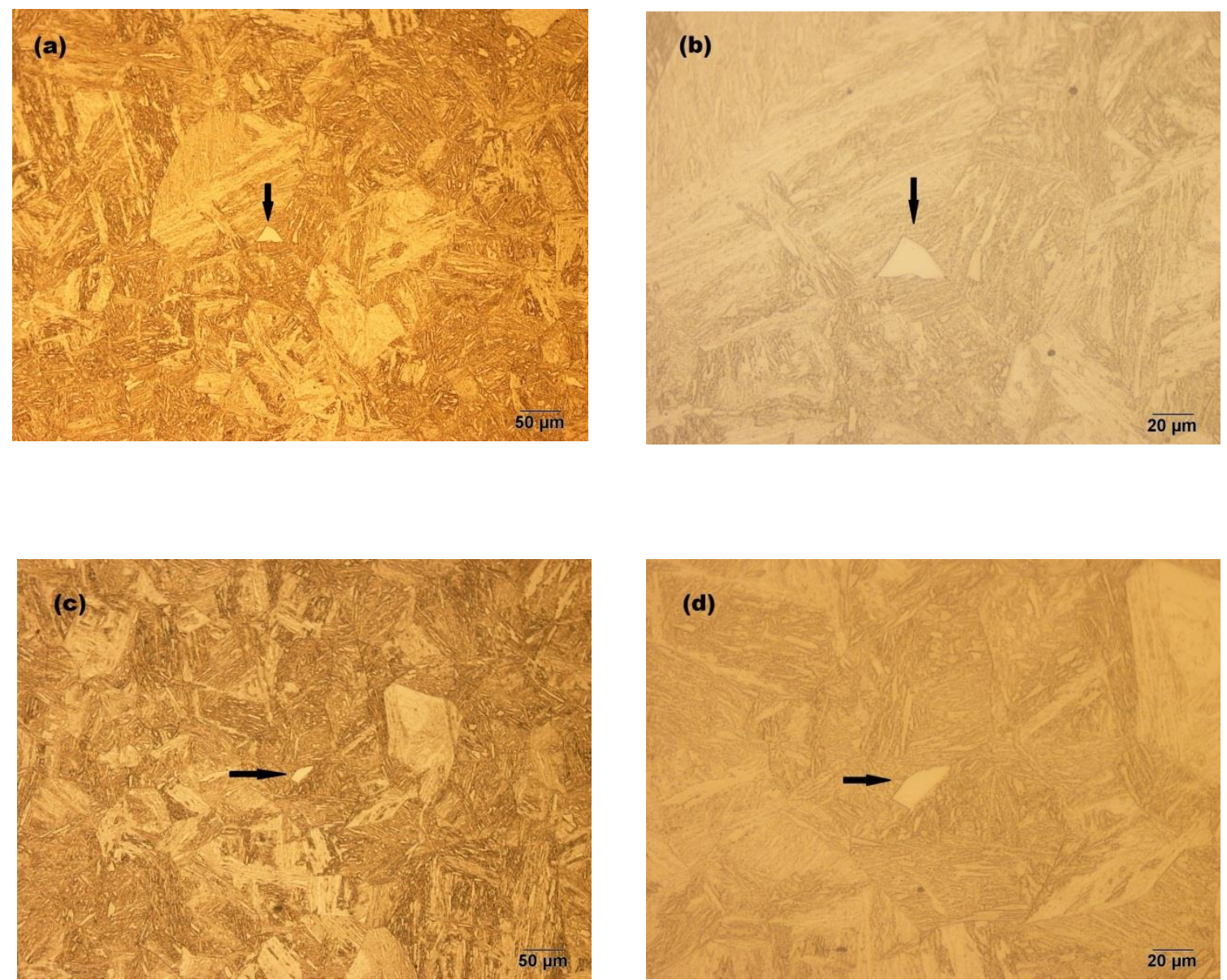

Figura 7: (a) y (b) Microestructura de martensita en listones, las flechas en negro indican placas aisladas de ferrita para un espécimen enfriado en forma continua a $1.5^{\circ} \mathrm{C} / \mathrm{min}$. bajo los aumentos de $20 \mathrm{X}$ y $50 \mathrm{X}$. (c) y (d) Las mismas observaciones para un espécimen enfriado a $3^{\circ} \mathrm{C} / \mathrm{min}$. bajo los mismos aumentos. 

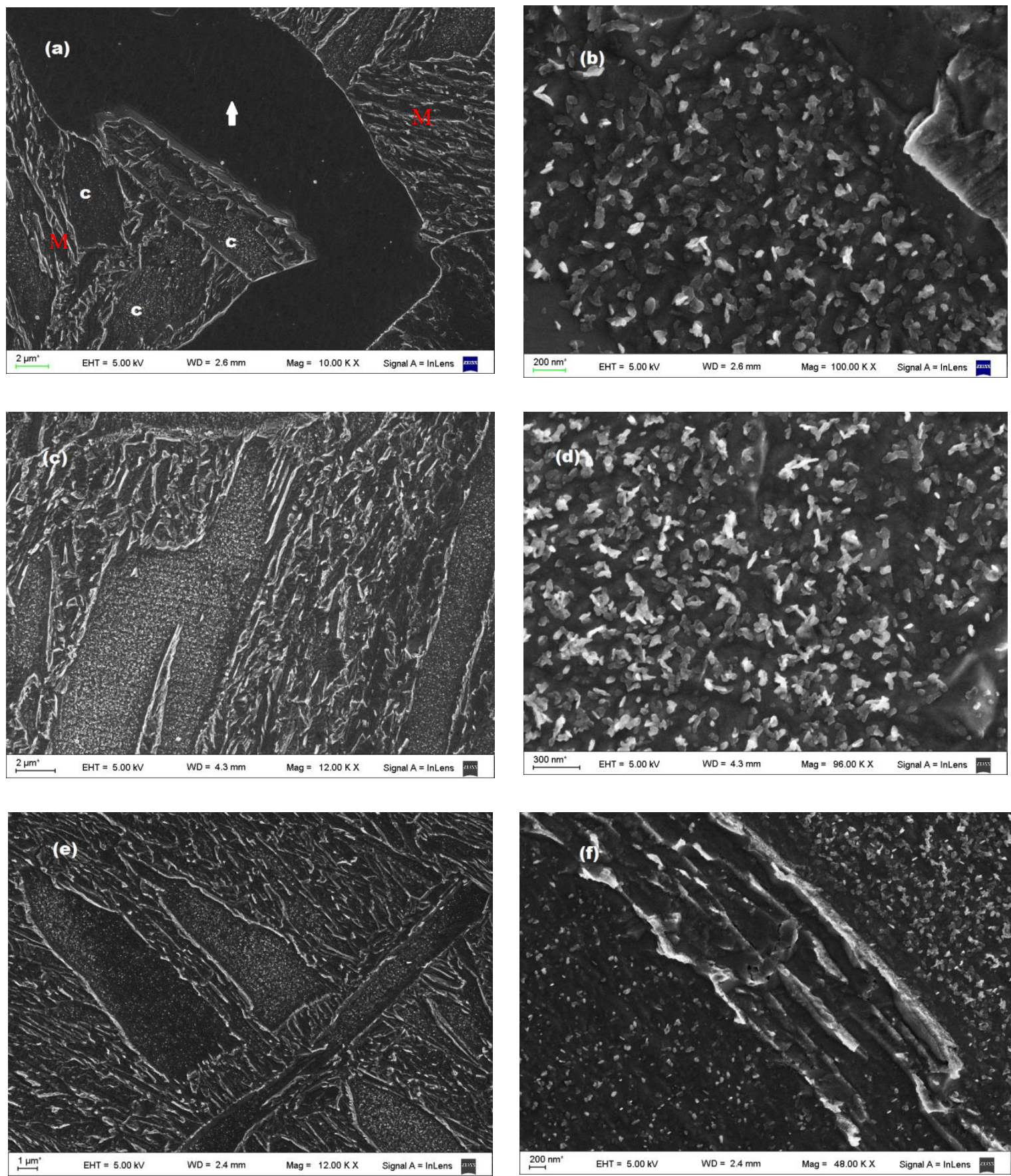

Figura 8: (a) Placa de ferrita (flecha blanca) nucleada en un punto triple austenítico y listones de martensita (M), en algunos casos con presencia de carburos (C) en un espécimen enfriado a $2^{\circ} \mathrm{C} / \mathrm{min}$, (b) ampliación de la región analizada en (a). La orientación preferencial que se advierte en los carburos es típica de los carburos presentes en la martensita. (c) listones gruesos con profusa precipitación y listones finos casi sin precipitación en el espécimen enfriado a $10^{\circ} \mathrm{C} / \mathrm{min}$, (d) ampliación de la región con precipitación; (e) ídem (c) para la muestra enfriada a $50{ }^{\circ} \mathrm{C} / \mathrm{min}$, (f): comparación de las regiones de listones gruesos con precipitación y finos sin precipitación para la muestra enfriada a $50^{\circ} \mathrm{C} / \mathrm{min}$.

Es importante mencionar que las muestras enfriadas a velocidades bajas, como 1.5 y $2^{\circ} \mathrm{C} / \mathrm{min}$. presentaron las mencionadas placas de ferrita tanto en el interior como en los bordes de las mismas; una posible explicación de este efecto es la descarburación en los especímenes durante los ensayos. En el espécimen enfriado a $3^{\circ} \mathrm{C} / \mathrm{min}$. no se observaron placas de ferrita nucleadas en los bordes de la probeta, solo se encontró un porcentaje minoritario de esta fase diseminada de manera irregular en el cuerpo de la misma. En las muestras enfriadas a 5,10 y $50^{\circ} \mathrm{C} / \mathrm{min}$. no se detectó la presencia de la fase ferrita. 


\section{DISCUSION}

El desdoblamiento o la ocurrencia de etapas dentro de la transformación martensítica ha sido ya observado e informado en la literatura previa para diferentes tipos de aleaciones $[1,10,11]$ incluyendo los aceros de alto $\mathrm{Cr}$ $[2,12]$. Las hipótesis propuestas para explicar este fenómeno han sido enmarcadas en los distintos protocolos experimentales y diferentes composiciones químicas nominales. Así, GARCÍA DE ANDRÉS et al. [11] apuntan a la transformación diferencial de distintas regiones de austenita, que coexisten con diferentes composiciones químicas debido a un insuficiente grado de homogeneización durante el ciclo térmico empleado. Otros autores, en cambio, sugieren que el fenómeno se produce por precipitación de carburos y/o crecimiento de carburos ya existentes, antes o después de producida la transformación [12]; dicha precipitación está, a su vez, asociada a la formación de listones anchos, que poseerían una temperatura de comienzo de formación de la martensita diferente de la correspondiente a los listones finos. Un tercer grupo de argumentos [10] postula que la modulación en la velocidad de transformación es plausiblemente consecuencia de la formación casi simultánea de bloques de listones de martensita dentro de todos los paquetes y en todos los granos, a lo largo del espécimen. Dicha simultaneidad aparecería a partir de condiciones de transformación localmente idénticas para la formación consecutiva de bloques adyacentes en un paquete. En fuerte contraste con esta última propuesta, se ha formulado también [1] la posibilidad de nucleación y crecimiento por pasos de regiones transformadas llamadas "cúmulos", a lo largo de un gran número de granos de austenita. La ocurrencia de una serie de máximos sucesivos en la velocidad de transformación se explicaría, dentro de este escenario, por el mecanismo de aceleración del crecimiento de cúmulos provisto por la formación autocatalítica de martensita, seguida de una desaceleración causada por las deformaciones por desajuste y las energías interfaciales entre las regiones transformadas y no transformadas.

En la evaluación de las diferentes hipótesis mencionadas arriba debe tenerse presente que las condiciones experimentales en nuestro caso difieren de las informadas en la literatura previa. Así, en las referencias [1] y [10] el enfriamiento se realiza a velocidad no sólo constante sino uniforme para todas las experiencias hasta llegar a una temperatura ligeramente superior a $\mathrm{M}_{\mathrm{s}}$, a partir de la cual sí se hace variar dicha velocidad. Esto asegura que la transformación a la martensita se realiza a partir de un estado metalúrgico "inicial"- en fase austenita- equivalente en todos los casos. En el presente trabajo se siguió un criterio diferente, a saber, se privilegió el acopio de información experimental sobre el diagrama de Transformación en Enfriamiento Continuo de la aleación bajo estudio, con la penalidad de obtener estados metalúrgicos "iniciales" (esto es, inmediatamente antes de la transformación a la martensita) diferentes para cada velocidad de enfriamiento. No obstante este hecho, tal como se anticipó en el comentario sobre la Figura 1 y siguientes, fue dable observar el fenómeno de desdoblamiento de la transformación austenitamartensita en un ámbito acotado de velocidades de enfriamiento. Más aún, el desdoblamiento se observó también en los casos en que se detectó la presencia de una pequeña fracción de ferrita en la muestra. Estas observaciones sugieren que el fenómeno es intrínseco a la transformación en sí y que su ocurrencia no dependería de variaciones en el estado metalúrgico de la matriz inmediatamente antes de su comienzo; en particular, de la fracción de austenita transformada a ferrita previamente.

\section{CONCLUSIONES}

Las observaciones por dilatometría de alta resolución, microscopía óptica y microscopía electrónica de barrido efectuadas sobre el conjunto de muestras de acero F82H ensayadas permitieron extraer las siguientes conclusiones:

a. Se detectó el fenómeno de desdoblamiento de la transformación martensítica en un ámbito de velocidades de enfriamiento comprendido entre 1.5 y $10^{\circ} \mathrm{C} / \mathrm{min}$.

b. Los gráficos de velocidad de transformación vs. temperatura presentaron un conjunto de máximos y mínimos, cuyo número parece aumentar con la disminución de la velocidad de enfriamiento.

c. La microestructura de la martensita obtenida se caracteriza por la presencia de listones engrosados con profusa precipitación en su interior, y listones finos con una densidad significativamente menor de precipitados.

d. En coexistencia con la matriz de martensita en listones se observó la presencia de placas aisladas de ferrita, en el rango inferior de velocidades de enfriamiento. La fase ferrita podría haber nucleado a alta temperatura, en el enfriamiento o bien en una secuencia de nucleación a alta temperatura y continuación del crecimiento durante la rampa de enfriamiento.

e. La observación del fenómeno de desdoblamiento para un rango de velocidades de enfriamiento 
diferentes entre sí y a la vez constantes para todo el intervalo de temperaturas explorado (esto es, sin asegurar la uniformidad del estado metalúrgico "inicial", inmediatamente previo al comienzo de la transformación) abre un nuevo campo de interrogantes sobre el mecanismo operante en dicho fenómeno.

\section{AGRADECIMIENTOS}

Este trabajo fue parcialmente financiado con aportes del Proyecto de Investigación Científica y Tecnológica 2170 -2014 del Foncyt-Mincyt (Argentina).

\section{BIBLIOGRAFÍA}

[1] VILLA, M., PANTLEON K., REICH, M., et al., "Kinetics of anomalous multi-step formation of lath martensite in steel", Acta Materialia, v. 80, pp. 468-477, Nov. 2014.

[2] LIU, C., LIU, Y., ZHANG, D., et al., "Research on splitting phenomenon of isochronal martensitic transformation in T91 ferritic steel", Phase Transitions, v. 85, n. 5, pp. 461-470, 2012.

[3] KOHYAMA, A., HISHINUMA, A, GELLES, D.S., et al., "Low-activation ferritic and martensitic steels for fusion application", Journal of Nuclear Materials, v. 233-237(Part 1), pp. 138- 147, Oct. 1996.

[4] TAVASSOLI, A.A.F., DIEGELE, E., LINDAU, R., et al., "Current status and recent research achievements in ferritic/martensitic steels", Journal of Nuclear Materials, v. 455, n. 1-3, pp. 269-276, Dec. 2014.

[5] American Society for Testing and Materials, ASTM A 1033-04 "Standard practice for quantitative measurement and reporting of hypoeutectoid carbon and low-alloy steel phase transformations", ASTM International, West Conshohocken, PA, USA, 2004.

[6] MATERNA MORRIS, E., Ferrite formation in F82H-mod. and OPTIFER II alloys, In: Scientific Report FZKA 5848, Proceedings of the Second Milestone Meeting of European Laboratories on The Development of Ferritic/Martensitic Steels for Fusion Technology, Karlsruhe, September 9-10, 1996.

[7] HURTADO-NOREÑA, C., DANÓN, C.A., LUPPO, M.I., et al., "Evolution of minor phases in a 9PctCr steel: effect of tempering temperature and relation with hydrogen trapping", Metallurgical and Materials Transactions, v. 46A, pp. 3972-3988, Sep. 2015.

[8] JONES, W.B, HILLS, C.R., POLONIS, D.H, "Microstructural evolution of modified 9Cr-1Mo steel", Metallurgical and Materials Transactions, v. 22A, pp. 1049-1058, May 1991.

[9] CARRIZO, D.A., "Comportamiento en transformación y caracterización microestructural de aceros de alta temperatura para reactores nucleares avanzados", Tesis de Maestría en Ciencia y Tecnología de Materiales, Instituto Sábato, UNSAM-CNEA, San Martín, Buenos Aires, 2012.

[10] LOEWY, S., RHEINGANS, B., RAMUDU MEKA, S., et al., "Unusual martensite-formation kinetics in steels: observation of discontinuous transformation rates", Acta Materialia, v. 64, pp. 93-99, Feb. 2014.

[11] GARCÍA DE ANDRÉS, C., JIMÉNEZ, J.A., ALVAREZ, L. F. "Splitting phenomena occurring in the martensitic transformation of $\mathrm{Cr} 13$ and $\mathrm{CrMoV} 14$ stainless steels in the absence of carbide precipitation", Metallurgical and Materials Transactions, v. 27A, n. 7, pp.1799-1805, Jul. 1996.

[12] TAO, X., HAN, L., GU, J., "Splitting phenomenon in martensitic transformation of X12CrMoWVNbN10-1-1 steel", International Journal of Materials Research, v. 106, n. 6, pp. 565-571, Jun. 2015. 